\title{
Kegiatan Center for Community Based Renewable Energy (CORE) Universitas Udayana Dalam Mendukung Pencapaian Sustainable Development Goals
}

\author{
CORE Universitas Udayana \\ Lantai 2 Gedung LP2M Kampus Bukit Jimbaran \\ Jl. Kampus Unud Bukit Jimbaran 80361 \\ Email: core@unud.ac.id
}

\section{PENDAHULUAN}

Pada tanggal 25 September 2015 bertempat di Markas Besar Perserikatan Bangsa-Bangsa (PBB), para pemimpin dunia secara resmi mengesahkan Agenda Tujuan Pembangunan Berkelanjutan (Sustainable Development Goals) sebagai kesepakatan pembangunan global. Tujuan dari SDGs itu disajikan dalam 17 tujuan seperti digambarkan pada ilustrasi di bawah.

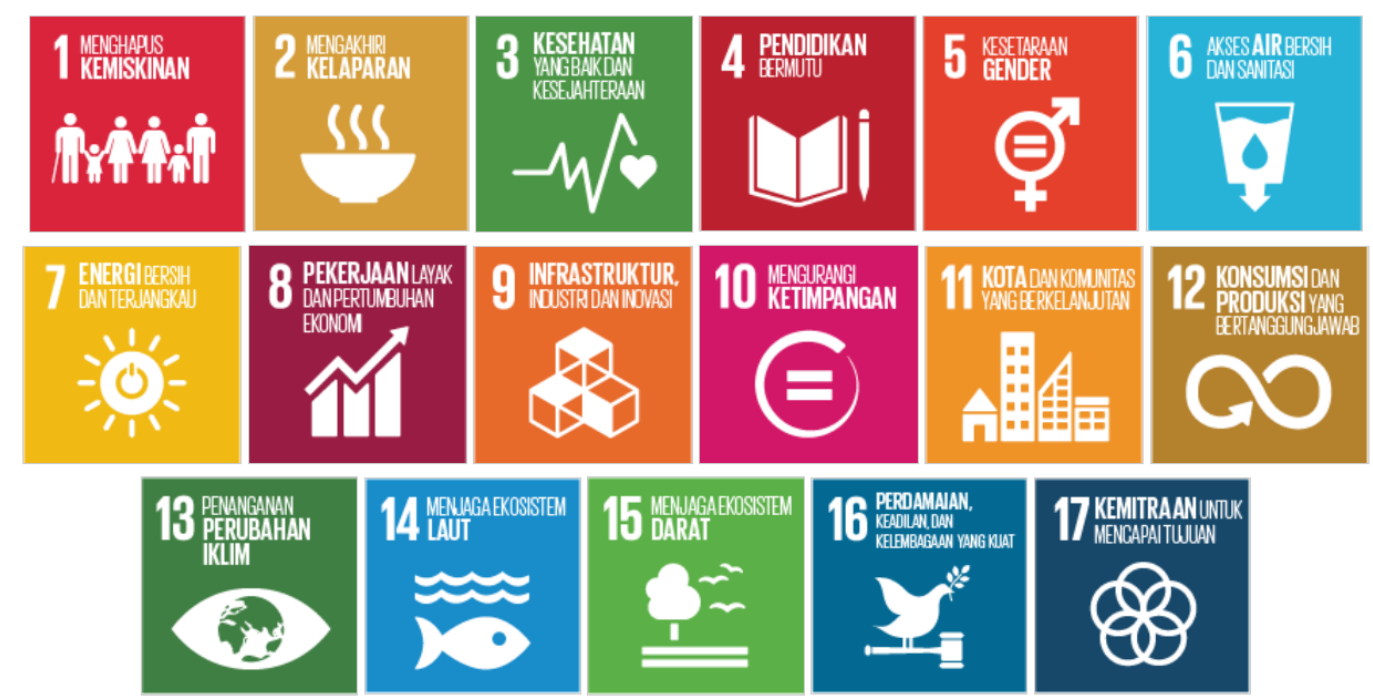

CORE Universitas Udayana dibentuk oleh Rektor Universitas Udayana berdasarkan SK Rektor No 210/UN.14/HK/2016 yang didukung oleh Konsorsium Perguruan Tinggi Hijau Indonesia yang didanai oleh Millenium Challenge Account Indonesia (MCA-I) Pemerintah Amerika Serikat. Sejak berdiri CORE telah melakukan berbagai kegiatan seperti pengkajian penerapan teknologi, penelitian terapan dan juga pengabdian masyarakat. Di samping itu, CORE juga telah berhasil membangun jejaring nasional dan internasional untuk mendukung perkembangan energi terbarukan di Indonesia.

\section{KEGIATAN CORE DAN KETERKAITAN DENGAN TUJUAN SDGs}

Dari 17 SDGs, aktifitas CORE Universitas Udayana berkaitan dengan beberapa tujuan SDGs sebagai berikut:

1. SDGs Tujuan 6: Air bersih dan sanitasi layak

2. SDGs Tujuan 7: Energi bersih dan terjangkau 
3. SDGs Tujuan 8: Pekerjaan layak dan pertumbuhan ekonomi

4. SDGs Tujuan 13: Penanganan perubahan iklim

Kegiatan CORE mencakup kegiatan pendampingan terhadap pemangku kepentingan seperti masyarakat, pemerintah kabupaten, pemerintah provinsi, perusahaan penyedia listrik dalam merancang, merevitalisasi, memelihara, mengoperasikan sistem teknologi listrik. CORE juga melakukan kajian teknis dan ekonomis terhadap penerapan suatu sistem teknologi untuk aplikasi sepisifik di masyarakat. Di samping itu, CORE juga aktif dalam menghubungkan sumber-sumber pendanaan eksternal baik dari lembaga nasional maupun internasional untuk mendukung implementasi kegiatan-kegiatan tersebut di masyarakat.

\section{CORE - SDGs 6: Air bersih dan sanitasi layak}

Ketersediaan air bersih masih merupakan salah satu permasalahan yang dihadapi masyarakat yang tinggal di wilayah terpencil atau remote area di Bali. Sebagai contoh, masyarakat di Dusun Ban, Desa Datah, Kecamatan Kubu, Kabupaten Karangasem kekurangan pasokan air bersih untuk kebutuhan sehari-hari. CORE telah membantu Pemerintah Provinsi Bali dalam merevitalisasi PLTS off-grid yang dibangun Pemerintah Pusat sebagai sumber tenaga listrik. Tetapi karena akhirnya listrik PLN telah masuk ke wilayah ini maka PLTS tersebut kemudian dimanfaatkan sebagai catu daya pompa air. Pompa air bertenaga listrik matahari ini mengangkat air dari sumber mata air yang ada di desa namun berada pada elevasi yang jauh dari wilayah pemukiman. Pompa ini mampu menyediakan sebagian kebutuhan air masyarakat.
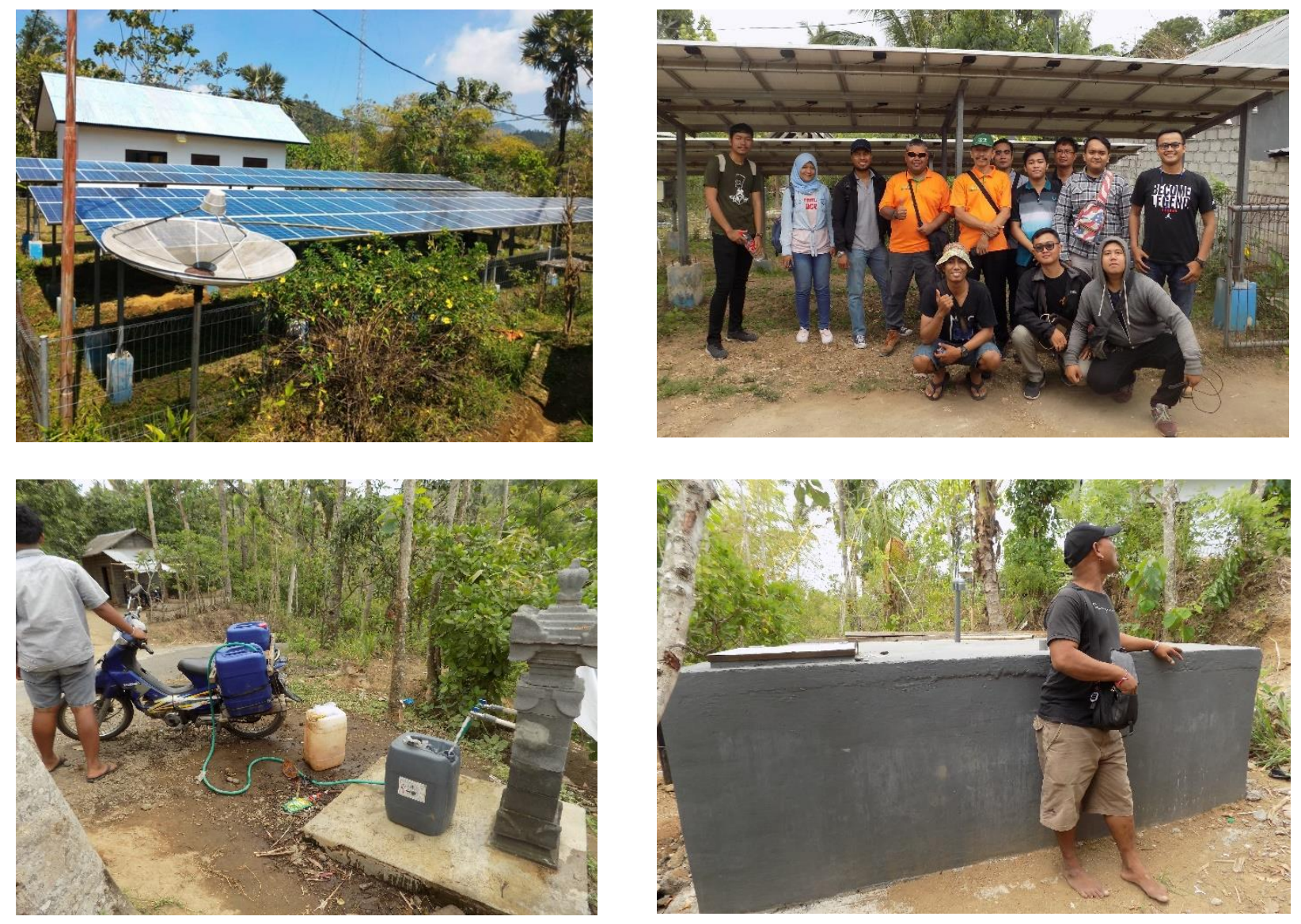

Ket foto: Revitalisasi PLTS off-grdi Datah untuk catu daya pompa air bersih bagi masyarakat. 


\section{CORE - SDGs 7: Energi bersih dan terjangkau}

Secara umum teknologi energi bersih relatif masih baru dan membutuhkan perubahan pola fikir dalam penerapannya dan selalu melakukan evaluasi terhadap penerapan teknologi tersebut sehingga didapat hasil yang optimal. Dalam konteks ini CORE memberikan masukan terhadap penerapan desain digester pada salah satu kelompok SIMANTRI di desa Kramas Gianyar. Dari hasil observasi lapangan didapat bahwa penerapan sistem biogas belum optimal sehingga hasil yang diperoleh juga masih bisa ditingkatkan. Rekomendasi yang diberikan antara lain pemilihan material digester, pengaturan komposisi kotoran dan air, serta sistem saluran air ke digester. Hal-hal ini akan membantu kelompok petani dalam mengelola kotoran sapi untuk dimanfaatkan sebagai sumber energi untuk memasak dengan kompor biogas.
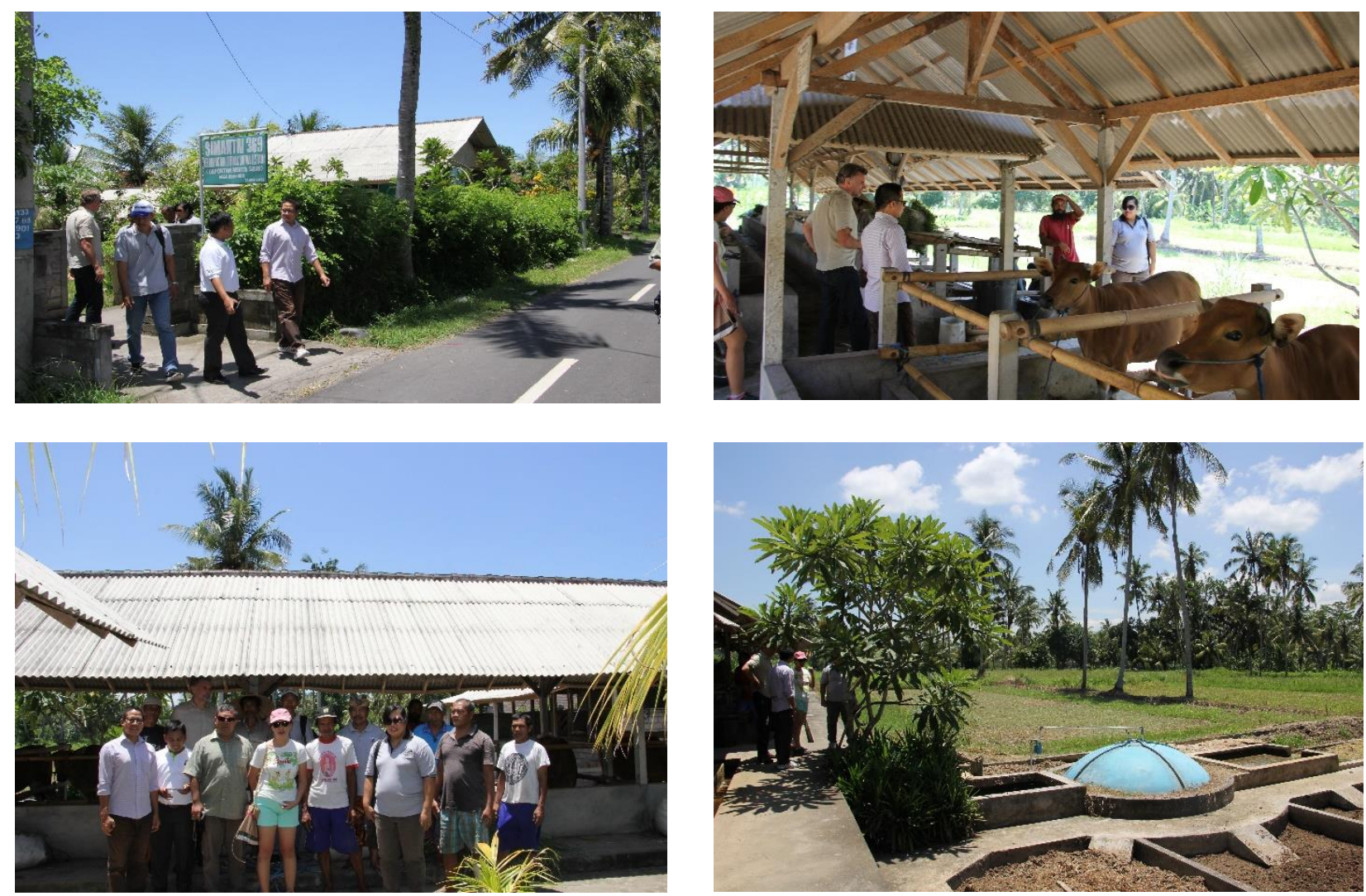

Ket foto: Pembinaan teknis dalam pengoptimalan produksi biogas sebagai bahan bakar kompor gas di SIMANTRI Keramas.

\section{CORE - SDGs 8: Pekerjaan layak dan pertumbuhan ekonomi}

Pertanian merupakan sektor penting kedua dalam Pendapatan Domestik Regional Bruto Bali setelah usaha akomodasi. Salah satu kendala perkembangan dan keberlanjutan pertanian di samping alih fungsi lahan adalah karena karakteristik wilayah persawahan. Sebagai contoh Subak Semagung dengan luas lahan lebih kurang 70 hektar mengalami kesulitan untuk melakukan penanaman padi yang di wilayah sekitarnya dilakukan sebanyak 2 kali setahun tetapi di Subak Semagung hanya dapat dilakukan sekali setiap 2 tahun akibat kurangnya pasokan air irigasi. Hal ini disebabkan karena lokasi dari Subak Semagung agak jauh dari sumber mata air sehingga air yang masuk ke wilayah Semagung sangat terbatas akibat serapan tanah yang agak berpasir dan juga adanya kebocoran pada saluran irigasi. 
CORE bekerjasama dengan Pemerintah Kabupaten Klungkung dan Toyama City Jepang mengajukan proposal kepada Kedubes Jepang Jakarta agar permasalahan kekurangan air irigasi Subak Semagung ini bisa diatasi. Outcome dari proyek Subak Semagung ini adalah tersedianya air yang cukup untuk irigasi Subak sehingga penanaman padi atau panen bisa ditingkatkan. Dengan demikian, petani Subak tidak akan beralih pekerjaan ke sektor lain yang memaksa mereka untuk melakukan urbanisasi dan meninggalkan potensi ekonomi desa yang sebenarnya baik.

Proyek pompa air bertenaga listrik di Subak Smeagung Tusan ini baru saja diserahkan dari Kedubes Jepang kepada Subak Semagung Tusan Klungkung. CORE akan tetap mendampingi Subak Semagung dalam mengoperasikan sistem teknologi tersebut agar bisa dimanfaatkan secara berkelanjutan. CORE juga akan melakukan berbagai kajian/ penelitian terkait penerapan energi terbarukan ini.
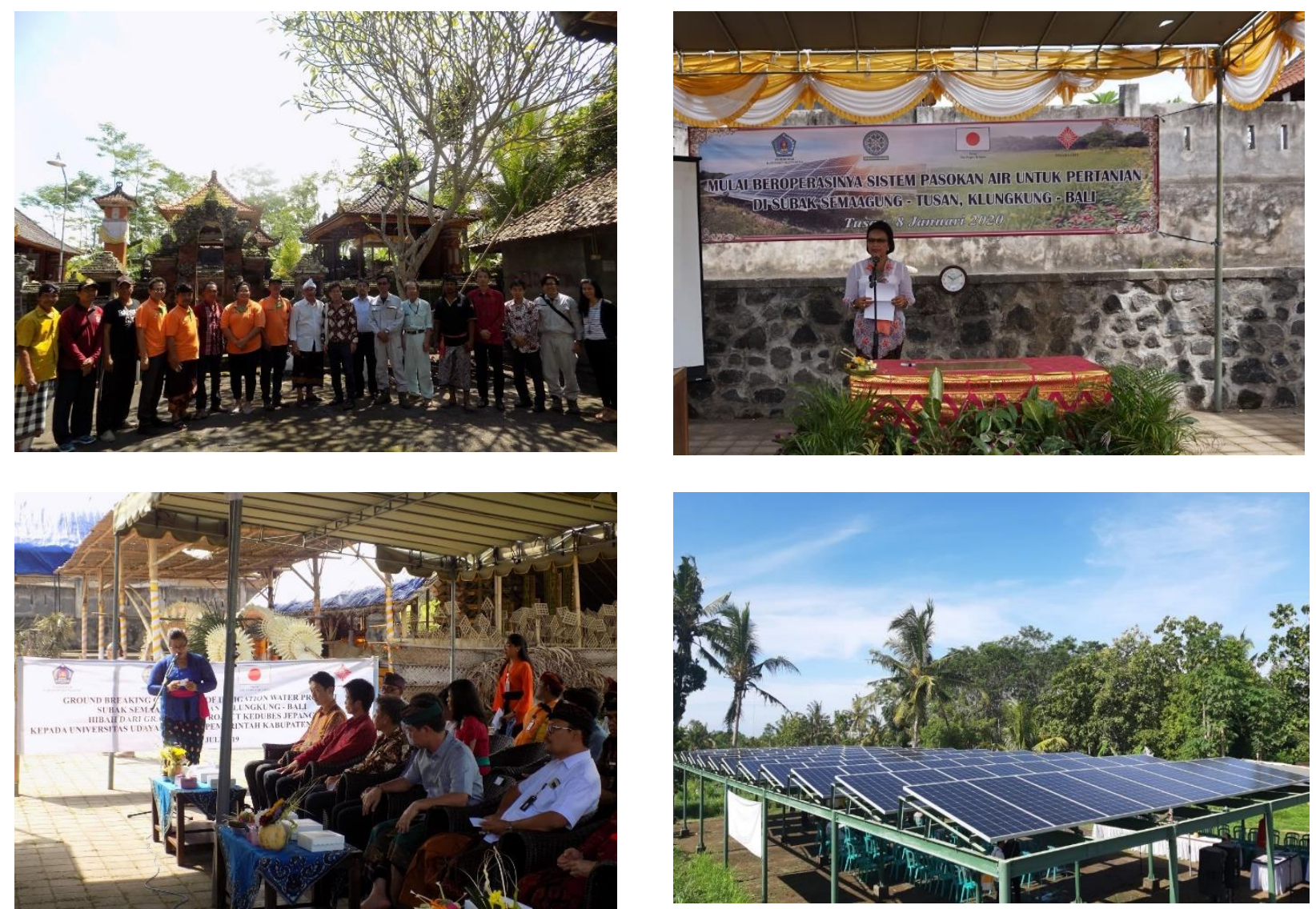

Ket foto: Pembangunan pompa irigasi bertenaga PLTS untuk Subak Semagung Tusan dengan dukungan Grassroot Grant dari Kedubes Jepang Jakarta.

\section{CORE - SDGs 13: Penanganan perubahan iklim}

Kegiatan CORE dalam mendampingi pemangku kepentingan untuk menerapkan pembangkit listrik sebagai catu daya pompa air merupakan salah satu upaya terkait penangan perubahan iklim. Penerapan teknologi energi bersih dalam bidang pertanian disamping membantu pertanian juga berdampak terhadap pengurangan emisi gas buang. Revitalisasi PLTS off-grid yang akhirnya tidak terpakai karena masuknya listrik ke wilayah tersebut dan menggunakan PLTS ini sebagai catu daya pompa air juga merupakan upaya pengurangan emisi gas buang. 
CORE juga secara aktif mendukung Pemerintah Provinsi Bali dalam upaya memperkuat posisi Bali dalam mempercepat tercapainya target energi bersih 2025. CORE membantu pemerintah Provinsi Bali dalam menyusun Rencana Umum Energi Daerah (RUED) dimana CORE bersama Pemerintah Provinsi Bali serta Dewan Energi Nasional mengidentifikasi potensi sumber-sumber energi bersih di Bali yang bisa digunakan untuk mendukung pencapaian target energi bersih nasional dalam konteks Bali.
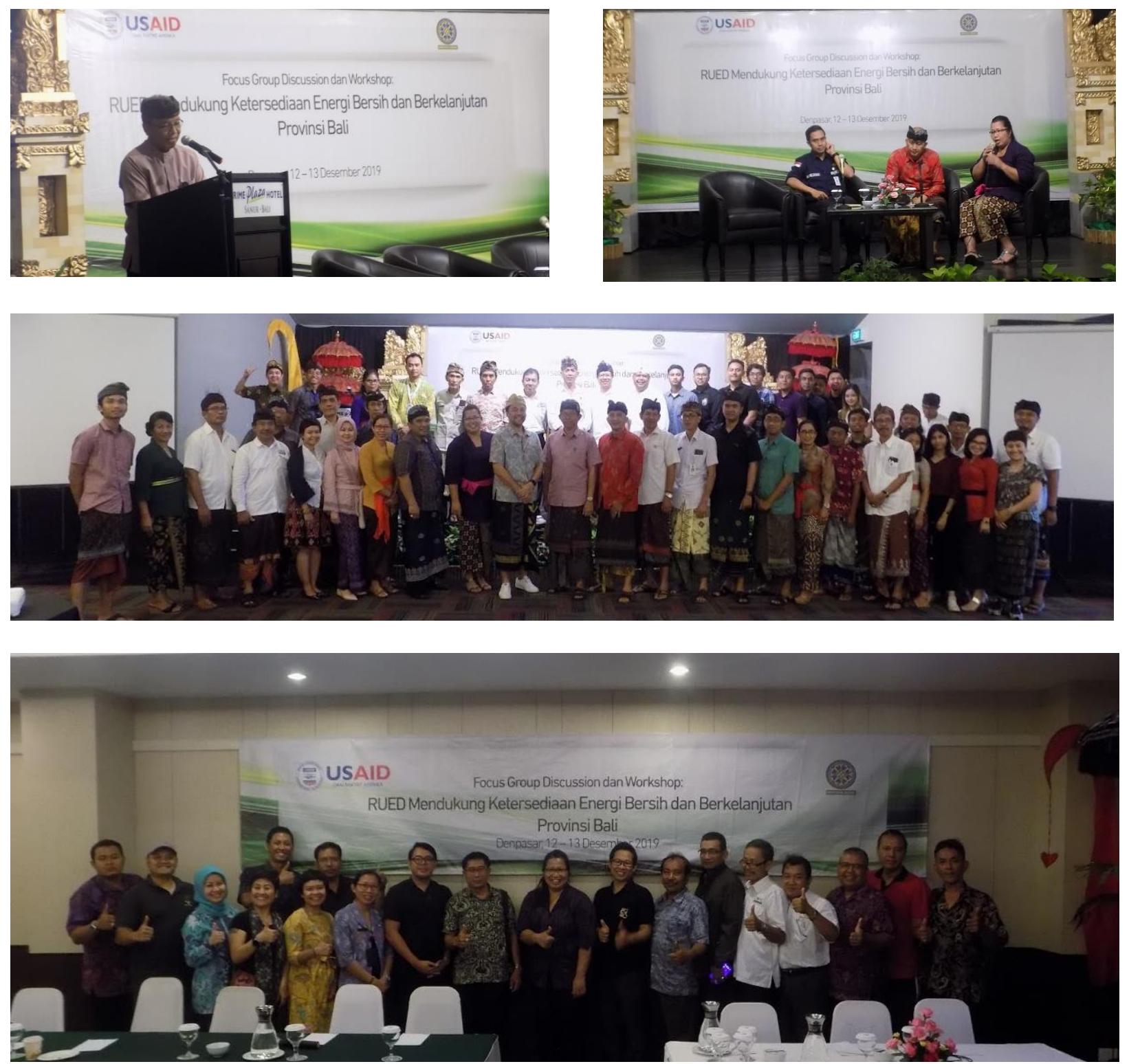

Ket foto: Ikut menyusun RUED Bali bersama OPD Pemerintah Provinsi Bali dan Pemerintah Pusat yang didukung oleh USAID.

CORE juga aktif mendukung Pemerintah Provinsi Bali dalam pengembangan Kendaraan Listrik Baterai sebagai salah satu upaya pengurangan gas rumah kaca dari sektor transportasi. Pemerintah Provinsi Bali telah mengeluarkan Peraturan Gubernur tentang kendaraan listrik. Saat ini sedang disusun rencana aksi untuk mengimplementasikan Peraturan Gubernur tentang kendaraan listrik dan energi bersih. 

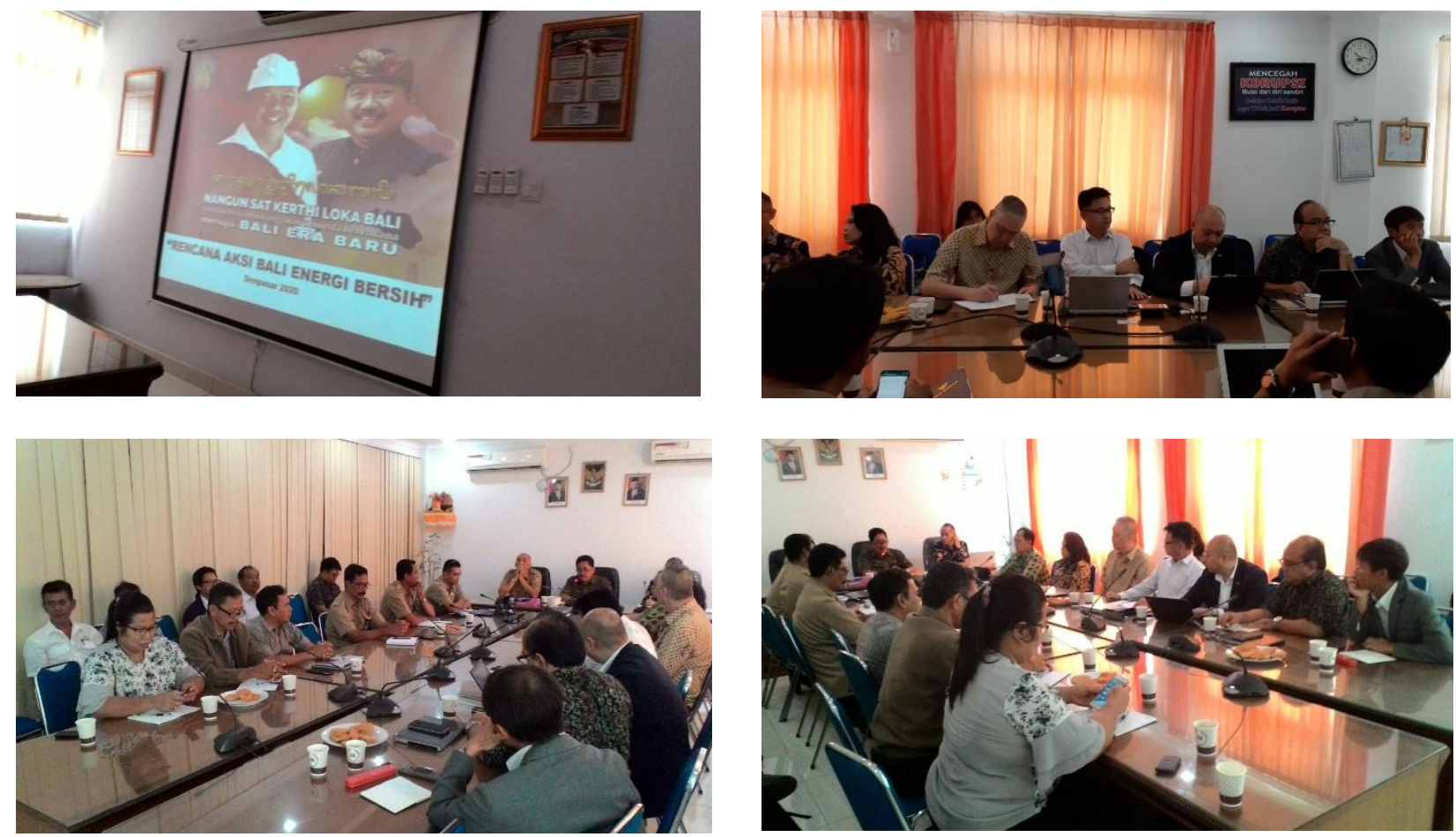

Ket foto: Bersama BAPPENAS, Dinas ESDM Bali, Panasonic Asia, Sureco Bali dalam mengkaji penerapan model dan teknologi baterai untuk mendukung kendaraan listrik serta smart building di Bali.

CORE secara aktif mendukung PT PLN Distribusi Bali bekerjasama dengan ITB untuk merancang Rencana Umum Kelistrikan Daerah Bali dimana di dalamnya dilakukan berbagai upaya untuk menurunkan emisi gas rumah kaca dengan penggunaan teknologi pembangkitan listrik yang lebih bersih dan juga energi terbarukan.
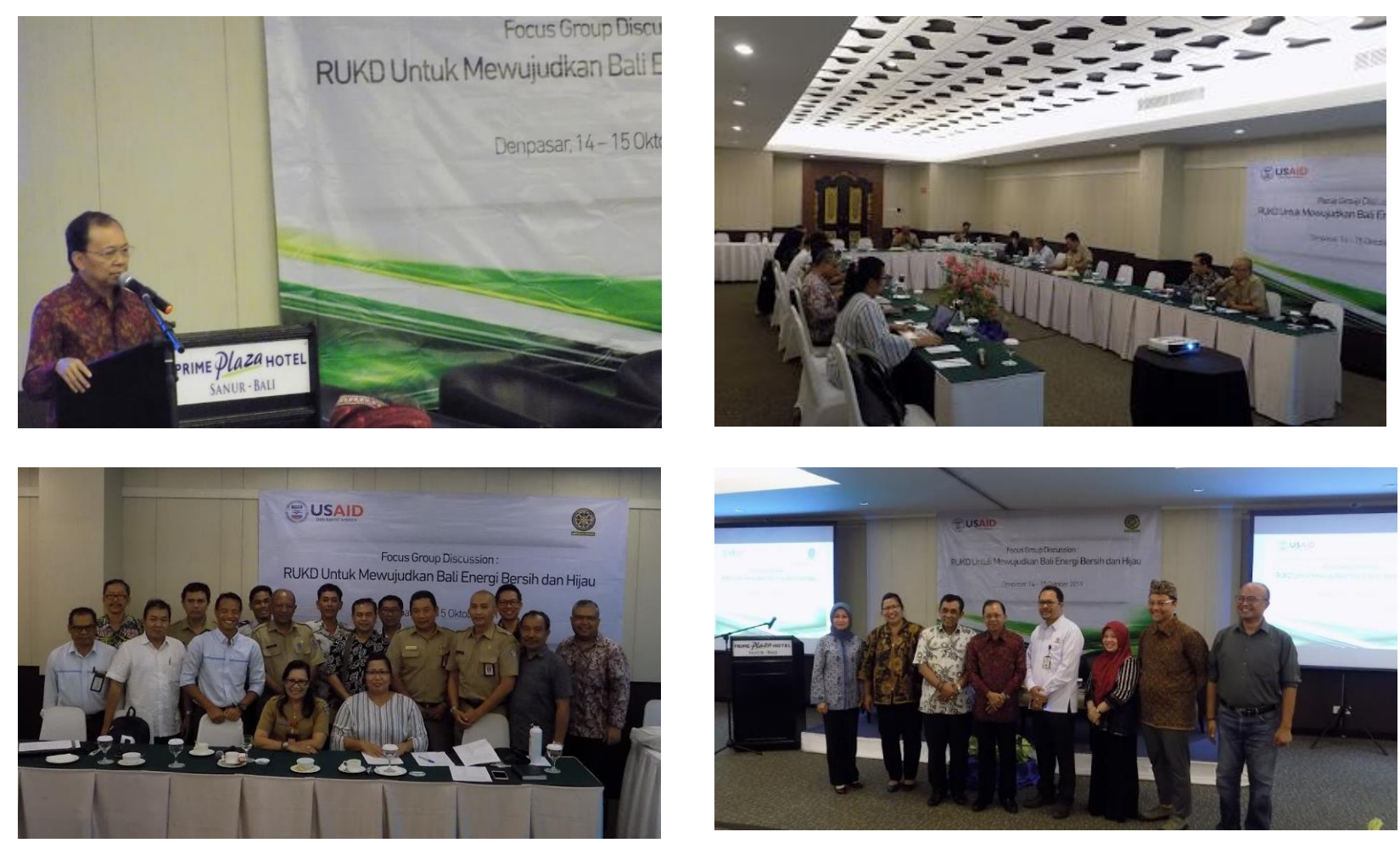

Ket foto: FGD dan Workshop Rencana Umum Keistrikan Daerah (RUKD) merupakan kerjasama COREPemprov Bali-USAid untuk meningkatkan peran energi bersih dalam sistem kelistrikan Bali. 
CORE aktif bekerjasama dengan PT Indonesia Power dalam mengkaji penerapan teknologi energi terbarukan untuk membangun smart micro grid.
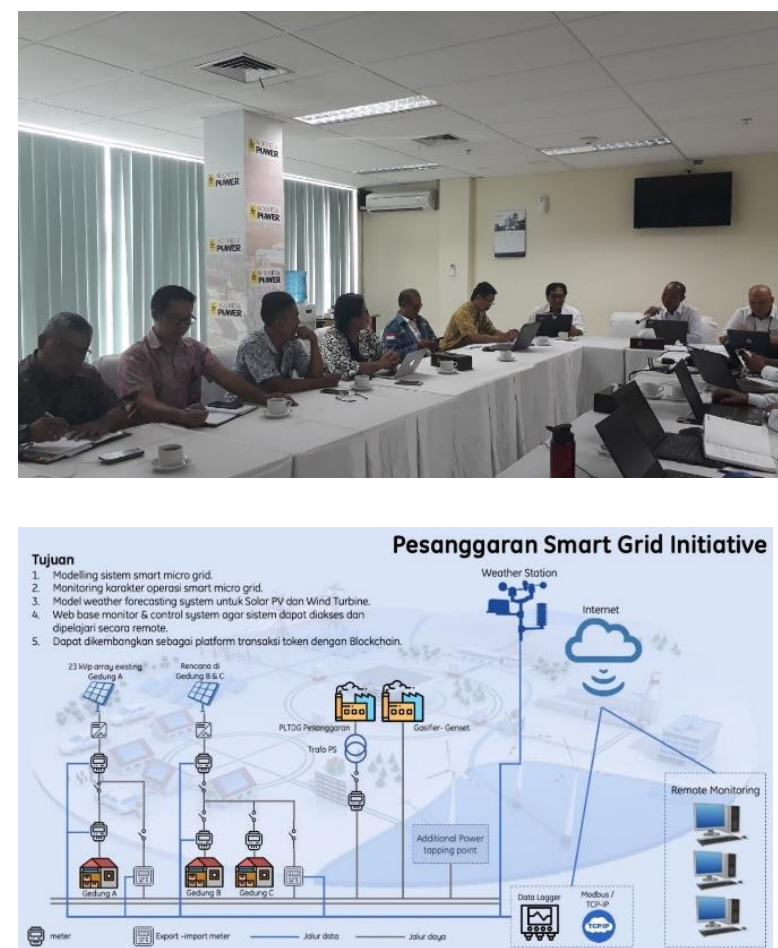
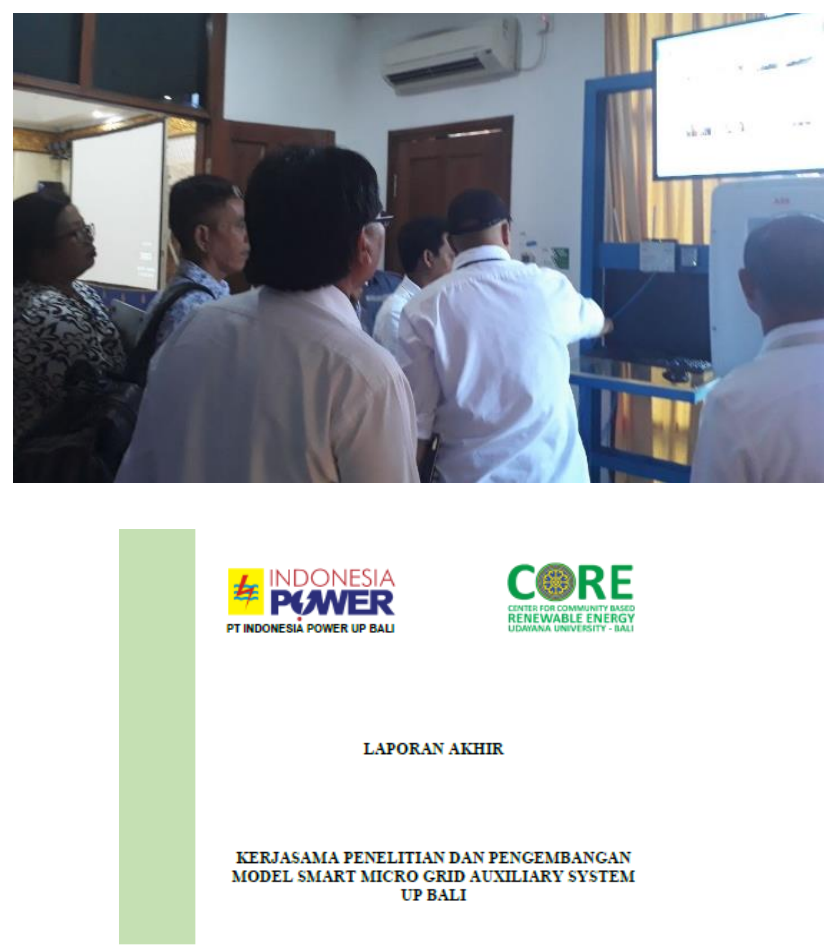

LAPORAN AKHIR

KERJASAMA PENELITIAN DAN PENGEMBANGAN
MODEL SMART MICRO GRID AUXIIIARY SYSTEM UP BALI

Ket foto: Kerjasama dengan PT Indonesia Power Bali dalam rangka pengkajian penerapan smart micro grid di Pesanggaran.

CORE aktif bekerjasama dengan Pemerintah Provinsi Bali dan juga LSM Green Peace untuk melakukan kajian secara lebih akurat untuk melihat apakah Bali bisa memenuhi target pembangunan Pembangkit Listrik Tenaga Surya sebesar $108 \mathrm{MW}$ sesuai target nasional yang ditetapkan untuk Bali. Berdasarkan kajian CORE yang telah menghasilkan buku Peta Jalan Pengembangan PLTS Atap Menuju Bali Mandiri Energi, Bali memiliki potensi yang sangat besar untuk mencapai target tersebut dan bahkan lebih. 

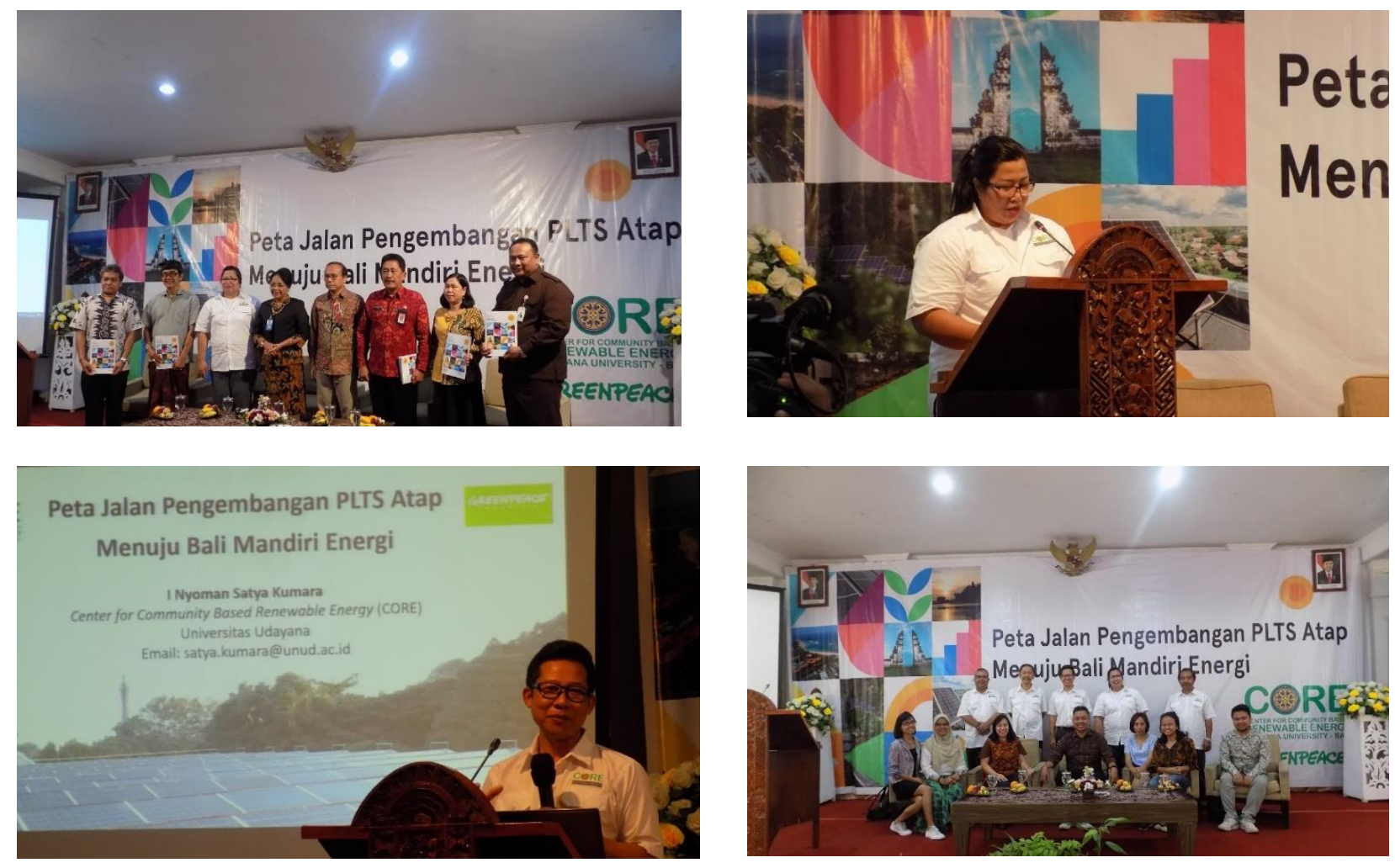

Ket foto: Peluncuran Peta Jalan Pengembangan PLTS Atap Menuju Bali Manidiri Energi bersama Rektor Universitas Udayana, Pemerintah Provinsi Bali, Greenpeace Indonesia, dan pemangku kepentingan energi di Bali.

\section{MAPPING KEGIATAN CORE DALAM KONTEKS GLOBALISASI, KEMITRAAN NASIONAL DAN INTERNASIONAL, SERTA KINERJA CAPAIAN DAN BIDANG UNGGULAN}

\section{CORE dan Internasionalisasi}

Dalam konteks internasionalisasi CORE sudah mengambil peran yang sangat baik dengan luasnya jejaring yang telah berhasil dikembangkan dan juga kegiatan penelitian dan community development yang telah berhasil dilaksanakan. Sebagian besar kegiatan-kegiatan CORE di dukung secara finansial dari jejaring yang telah berhasil dibangun. Berikut adalah ilustrasi jejaring CORE dengan lembaga nasional dan internasional. 


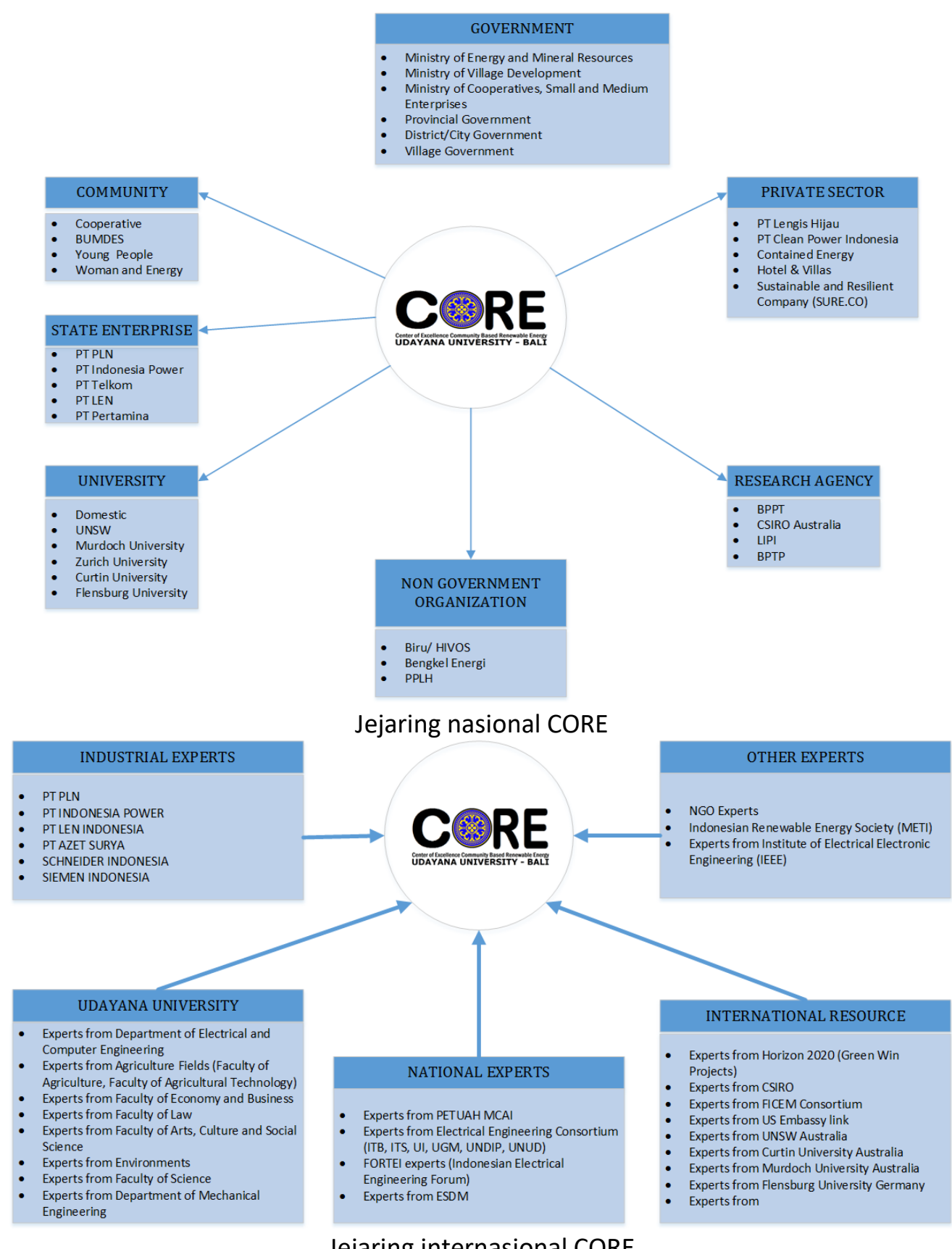

Jejaring internasional CORE

\section{CORE dan Kemitraan Nasional dan Internasional}

CORE telah berhasil menjalin kemitraan nasional dan internasional seperti digambarkan pada bagian internasionalisasi. Beberapa kegiatan yang telah berhasil diimplementasikan dari kemitraan tersebut antara lain:

1. Pembangunan 4 unit PLTMH di World Heritage Site Jatiluwih dan pemasangan lampu penerangan jogging track. Kegiatan ini melibatkan Pemerintah Provinsi Bali, Pemerintah Kabupaten Tabanan, Kementerian Dalam Negeri, Japan International for Coperation Agency (JICA), dan masyarakat Jatiluwih Tabanan.

2. Pembangunan pompa air irigasi bertenaga listrik untuk Subak Semagung Tusan Klungkung dengan dukungan finansial dari Kedubes Jepang Jakarta. Kegiatan ini melibatkan Pemerintah Kabupaten Klungkung, Kementerian Dalam Negeri, Pemerintah Toyama Jepang, dan masyarakat Subak Semagung Klungkung, serta perusahaan Suiki Kogyo Japan. 
3. Pelaksanaan kerjasama sosialisai energi bersih dengan Yayasan Perspektif Baru untuk memotivasi annak muda/ mahasiswa dalam menggali dan memenfaatkan energi bersih. Kegiatan ini melibatkan Yayasan Perspektif Baru Jakarta.

4. Pelaksanaan kajian Pembangkit Listrik Tenaga Surya untuk Bali. Kajian ini bertujuan untuk menghasilkan buku peta jalan pengembangan PLTS menuju Bali mandiri energi. Kegiatan ini melibatkan Pemerintah Provinsi Bali, Dewan Energi Nasional (DEN), dan Greenpeace Indonesia.

5. Pelaksanaan kegiatan FGD dan Workshop terkait penyusunan RUED dan RUKD bagi pemangku kepentingan energi di Bali. Kegiatan ini melibatkan Dewan Energi Nasional, Institut Teknologi Bandung, Pemerintah Provinsi Bali, dan US Aid dalam program Indonesia Clean Energy Development (ICED) I dan ICED II.

\section{CORE dan Kinerja Capaian dan Bidang Unggulan}

Capaian dan bidang unggulan CORE adalah energi terbarukan dan khususnya kajian dan penerapannya yang berbasis masyarakat. Energi terbarukan mencakup Pembangkit Listrik Tenaga Surya (PLTS), Pembangkit Listrik Tenaga Mikrohidro (PLTMH), Pembangkit Listrik Tenaga Bayu (PLTB), Pembangkit Listrik Biomasa (PLTSa) dan jaringan kelistrikan cerdas (smart grid).

\section{Daftar Pustaka}

GUNAWAN, N. Surya; KUMARA, I. N. Satya; IRAWATI, Rina. UNJUK KERJA PEMBANGKIT LISTRIK TENAGA SURYA (PLTS) 26,4 KWP PADA SISTEM SMART MICROGRID UNUD. Jurnal SPEKTRUM, [S.I.], v. 6, n. 3, p. 19, sep. 2019, https://doi.org/10.24843/SPEKTRUM.2019.v06.i03.p01.

H. L. Bestari, I. N. S. Kumara and W. G. Ariastina, "Performance Evaluation of 25 KW Community Microhydro in Seloliman Village East Java," 2018 International Conference on Smart Green Technology in Electrical and Information Systems (ICSGTEIS), Bali, Indonesia, 2018, pp. 144-149. doi: 10.1109/ICSGTEIS.2018.8709110

I. Kumara, T. Urmee, Y. Divayana, I. Setiawan, A. Pawitra and A. Jaya, "Implementation of Grid-connected PV Plant in Remote Location in Sumbawa Island of Indonesia: Lesson Learned," 2018 International Conference on Smart Green Technology in Electrical and Information Systems (ICSGTEIS), Bali, Indonesia, 2018, pp. 203-209. doi: 10.1109/ICSGTEIS.2018.8709105

I.A.D Giriantari, W.G. Ariastina, I.N.S. Kumara, Fueling Community from SIMANTRI Bali Integrated Farming System, Policy Brief, Konsorsium Petuah 2016

I.N.S. Kumara, I. A. D. Giriantari, W. G. Ariastina, "On The Potential and Progress Of Renewable Electricity Generation in Bali," 2014 6th Int. Conf. Inf.

http://ieeexplore.ieee.org/stamp/stamp.jsp?tp=\&arnumber=7007944\&isnumber=7006983

I.N.S. Kumara, I. A. D. Giriantari, W. G. Ariastina, W. Sukerayasa, N. Setiawan, C. G. I. Partha, “Peta Jalan Pengembangan PLTS Atap : Menuju Bali Mandiri Energi, Center For Community Based Renewable Energy (CORE) Universitas Udayana, Greenpeace Indonesia, Bali,2019.” 10.31219/osf.io/83yxv

I.P.E. Saskara, I.N.S. Kumara, I.W. Suerayasa, Comparison of PV Rooftop Energy Production at Denpasar City Office Building, Proceeding ICSGTEIS 2018, 10.31219/osf.io/qh7fa

KRISTIAWAN, H.; KUMARA, I.N.S.; GIRIANTARI, I.A.D.. Potensi Pembangkit Listrik Tenaga Surya Atap Gedung Sekolah di Kota Denpasar. Jurnal SPEKTRUM, [S.I.], v. 6, n. 4, p. 66-70, dec. 2019. ISSN 2684-9186. Available at: <https://ojs.unud.ac.id/index.php/spektrum/article/view/55330 
O. I. Sanjaya, I. A. D. Giriantari, and I. N. S. Kumara, "Perancangan Sistem Pompa Irigasi Pembangkit Listrik Tenaga Surya ( PLTS ) Untuk Pertanian Subak Semaagung," vol. 6, no. 3, pp. 114-121, 2019.

https://doi.org/10.24843/SPEKTRUM.2019.v06.i03.p16

P.D. Sari, I.N.S. KUmara, THE DEVELOPMENT OF JATILUWIH MICRO-HYDRO POWER PLANTS TO SUPPORT TOURISM DESTINATIONS, ISCECE 2018

VIDHIA KUMARA, Ketut; SATYA KUMARA, I Nyoman; ARIASTINA, Wayan Gede. TINJAUAN TERHADAP PLTS 24 KW ATAP GEDUNG PT INDONESIA POWER PESANGGARAN BALI. Jurnal SPEKTRUM, [S.I.], v. 5, n. 2, p. 26-35, dec. 2018. ISSN 2684-9186, https://doi.org/10.24843/SPEKTRUM.2018.v05.i02.p04.

WICAKSANA, M.R.; KUMARA, I.N.S.; GIRIANTARI, I.A.D. UNJUK KERJA PEMBANGKIT LISTRIK TENAGA SURYA ROOFTOP 158 KWP PADA KANTOR GUBERNUR BALI. Jurnal SPEKTRUM, [S.I.], v. 6, n. 3, p. 107-113, sep. 2019. ISSN 2684-9186, https://doi.org/10.24843/SPEKTRUM.2019.v06.i03.p15

YAYA PUTRA PRATAMA, I Dewa Gde; SATYA KUMARA, I Nyoman; SETIAWAN, I Nyoman. POTENSI PEMANFAATAN ATAP GEDUNG PUSAT PEMERINTAHAN KABUPATEN BADUNG UNTUK PLTS ROOFTOP. Jurnal SPEKTRUM, [S.I.], v. 5, n. 2, p. 119-128, dec. 2018.

https://doi.org/10.24843/SPEKTRUM.2018.v05.i02.p15. 